\title{
30 Years after the New Museology: What's Changed?
}

I am currently chief executive of the Horniman Museum and Gardens in London, but in order to explore what has changed since 1989 when "The New Museology" was published, I want to go back a bit further. And please forgive me if my reflections are rooted primarily in the Anglo-phone world; this has been the context in which I have worked over my career.

In September 1982, after an archaeology degree at Cambridge, I went to the University of Leicester to do a one-year postgraduate course in Museum Studies, something they had been offering since the mid 1960s. It was a very practical course, aimed at giving people the skills and understanding to go and work in a museum. So we did sessions on labelling objects, writing press releases, documentation, practical management and so on. There was really no "theory", except a little about communication and education, which was from a psychological background. There was some quasi-philosophical thinking such as Duncan Cameron's proposition that a museum should be a forum, not a temple (Cameron 1971), and Hugues de Varine's writings about ecomuseums and the role of museums in society (Varine 1978). But there was pretty well no consideration of politics, ideology, representation or any kind of critical approach to museums.

In parallel, though, of course, a more critical turn was taking place in the wider social sciences through the influence in particular of French theorists such as Foucault, Derrida, Althusser, and Bourdieu, and through German academics of the Frankfurt School, such as Adorno, Horkheimer, Marcuse, and Habermas, which began to provide a language to critically analyse history and institutions such as museums.

From this background, a critical art history began to develop - sometimes also called "The New Art History" from the early 1980s, and at the same time archaeologists and anthropologists developed material culture theory, which provided 
a way for museum people to develop a theoretical framework with which to critically analyse objects and processes of ideology, representation, domination, and resistance. Much of this came out of Cambridge where I had done my degree, through the work of Hodder, Tilley, Miller, and others. After my practical museum studies course in Leicester, I returned to Cambridge to do a $\mathrm{PhD}$, where, after an unsuccessful start looking at the Bronze Age archaeology of Austria, I decided to change topics to look at the issue of the public's attitudes to the past, and why large sections of the population did not visit heritage sites. I discovered the work of Pierre Bourdieu and his work The Love of Art: European Art Museums and their Public (1990), which I later translated from French into English.

At the same time, Susan Pearce had taken over the Leicester Museum Studies department, who was a strong follower of the writings of material culture theorists. It was her influence in Leicester that really started a critical approach to museum studies.

The key moment here was a big international conference, in Leicester, in 1987, called "Museum Studies in Material Culture", which was published in 1989 (Pearce 1989). The success of the conference and book sparked real interest and a movement of critical approaches to the analysis of museums. For me, this is the $30^{\text {th }}$ anniversary that is more significant than the Peter Vergo book, published in the same year. Vergo and most of the contributors came from an art history background, and their contributions, while very good and critical, were really an extension of what was already going on in mainstream art history at that time. Vergo's book, however, had a good title and made a bigger splash, being also published with a larger publisher compared to the Pearce book, and the term "The New Museology" took off in the same way that "The New Archaeology"' had in the 1970s: like that, it was not a seismic shift but an evolution, but it did represent a significant change.

Be that as it may, 1989 does usefully mark the beginning of a paradigm shift in museology, from a practical vocational discipline to a thoroughly academic, critical discipline. Since then, the whole landscape for museums and museum studies has shifted hugely. I will not explain these changes in detail but I thought a summary would be useful, and then I will move on to look at what has not changed, and what we need to do in the future.

First, of course, museum studies has become a proper academic field, with its own set of research questions. When I was studying there was one museum studies course in the UK (Leicester) and one on gallery studies (Manchester). Now there are 78 embracing museum, gallery and heritage studies, producing hundreds of postgraduate students each year, and scores of PhDs. This has been accompanied by an explosion of publications with perspectives from art history, archaeology, history, sociology, anthropology, geography, natural sciences, architecture, tourism, and so on. Through this was have had 30 years of people entering the museum profession who were versed in the critical language of museum stud- 
ies, and so we have had a generation of people who have begun to bring critical perspectives into what is otherwise a fairly conservative field.

So, what has changed in museum studies is:

- A general introduction of criticality and complexity into the analysis of museums.

- A recognition of multiple narratives and a critique of singular views of history; an understanding of the political nature of museums.

- Museums as sites of contestation - artists often used as catalysts (e.g. Fred Wilson "Mining The Museum" in 1992).

- Better understanding of critical histories of museums and the particular contexts in which they have been developed.

- Hence, giving voices to those who were previously excluded or silenced: women, working classes, minorities.

- A focus on audiences; an understanding of the cultural barriers to participation; improvements in education and communication; outreach, cocuration, introducing subjects of interest to wide audiences and not just elites.

- Evaluation of the museum experience; an anthropology of museum participation.

- Understanding of the role of museums in society, including place-making and identity formation, citizenship, learning and skills, health and wellbeing, and economic (including culture-led regeneration).

Despite this 30 years of development, there are still a significant number of areas where much still remains to be done.

One of these is to bridge the gulf between academic museum studies and museum practice. I am one of the few museum directors who has also been an academic museologist and I can see that whilst museology has undergone a revolutionary paradigm shift over the last 30 years, it has opened up a large gap between academia and the museum profession. Whilst students from museum studies courses take up museum jobs, they rarely have the time to keep up with current literature, or have the ability to make changes. So, one of the things we have to work on is to narrow this gap - there is a danger that museum studies becomes a self-referential academic discipline, with an audience of fellow museologists but no impact on museums themselves.

An example of this is our understanding of quite why they are so much more popular than they were: from the critiques, you would think that museums are sites of oppression and social division. But as a museum director, I see that people choose to come to museums in huge numbers and they find enjoyment, inspiration, fun, laughter there, as well as learning and provocation. We have not really developed an adequate understanding of why museums are so popular, whether with international tourists at the BM or amongst local communities - they are about pride of place as well as being safe inclusive places. At the Horniman, we 
have a strong social and environmental agenda, as I will explain, but our majority audiences are families with small children who run around enjoying the stuffed animals, etc., and having a good time with their family. We do not really value this or see it as something worthy of academic enquiry.

But at the same time this great popularity in museums has been still restricted to certain sections of the population. In England, national museums are free, but the people who have mostly taken advantage of this are middle class people who already visit museums. The Horniman, although it has nearly a million visits a year, is actually less diverse than it was 30 years ago.

So, one of the great remaining challenges is how to make museums actually properly inclusive; how to bring about mass participation from wider audiences. Others include:

- Critical understandings of the role of stored collections as a mass archive, and the role of disposal and collecting.

- The role of digital - are we in a post-material phase?

- Confronting difficult histories such as colonialism, and the issue of repatriation.

- Finally - Integrating "the natural world" into our theory of museology, and thence looking at museums and the climate, pollution and biodiversity crises.

To me, these last two are the greatest remaining challenges, and I want to dedicate the rest of my text to this subject, because it also highlights a whole series of other issues about the future of museums and of museology.

When I took over the Horniman, I realised that there had not been a lot of museological thinking about some of the things that were preoccupying us: the climate and environmental crisis, extinction, air and plastic pollution. I realised that for most of the time since its emergence as a distinctive critical field in the 1980s, museum and heritage studies have primarily been human-centred subjects, because they emerged from disciplines like archaeology, anthropology and art history, with their focus on human activity, material culture and critical theory.

In cabinets of curiosities, we do not see this divide, but with the Enlightenment, Judeo-Christian thought separated nature and culture, allowing it to be exploited, dominated, and controlled; seen as a hostile encumbrance to progress and a resource to bring riches. It is the legacy of this thinking that has allowed delay in actions to tackling climate, pollution and diversity, for Donald Trump's administration to disavow science and deny climate change, and Jair Bolsonaro to condone the accelerated destruction of the Amazon rainforest.

This separation of nature from culture has had a fundamental impact on the development of our own fields. For museums it has led to the separation of dedicated natural history museums (for example the BM was integrated with its natural history collections till they were hived off to form the NHM which opened in 1881) and even within global museums like Manchester, the Horniman and most 
large regionals, natural history was presented in separate galleries, often some way from displays of human cultures which lived in the same environments.

When I was a $\mathrm{PhD}$ student, museology did not really encompass natural history and the environment, particularly from a critical perspective. People who were natural history or earth science curators did not seem to be theoretical: they were working within a scientific paradigm that had little truck with for example post-colonial theory, but they were doing often vital practical work to highlight species decline, campaigning about the Red List of endangered species, and gathering evidence for change and loss. Our natural history collections are an incredible databank of biological diversity over some 200 years, much of it from a time before major extinctions set in. Our account of what critical museology is needs to encompass these future-oriented narratives of preservation and rescue.

Environmental education was, and is, seen as a vital function of museums, but it has usually employed a top-down deficit model, which thought that education would lead to appreciation, which would lead to care and hence preservation of species and their habitats.

There was of course critical museology brought to bear on natural history and environment, such as Donna Haraway's classic article on "Teddy Bear Patriarchy" (1984), but they tended to critique representations of the natural world from the perspective of what they said about the society that had produced them. Hugues de Varine's concept of the ecomuseum, and Peter Davis's subsequent work on them (Davis 1999), were all pretty much about human activities taking place within landscapes - sometimes industrial ones - which were about preserving them and keeping them static, often with a strongly nostalgic component. Again: the main focus was on people.

For a long time, though, the idea that nature and culture can be seen as separate realms has been criticised, partly because we cannot find anywhere on earth, including the deep oceans, that has not been affected by people, particularly in terms of plastic and particulate pollution. Some scholars such as Swyngedouw have suggested that nature should be seen as 'socio-environmental arrangements' (Swyngedouw 2013), which is a horrible phrase, or perhaps better, as Gandy suggests, "seeming nature" (2002: 110).

My contention, then, is that the historic nature-culture divide has affected all areas of museology, including the physical structures of museums, and different paradigms of thinking between humanities and scientific disciplines in museums, and has led to a blindspot in museological thinking. First, let me look at what the impact of the perpetuation of this divide has been.

You could argue that it does not matter that much: after all, most museums actually do deal with human cultures, whether they are museums about particular people, particular kinds of material culture (fine art for example), or about human histories. There are relatively few natural history museums, and natural history galleries are far outnumbered by cultural ones. 
But it does matter, for two main reasons. First, I think that the divide leads to a partial account of human history in museums: accounts of slavery and colonial exploitation, and the Industrial Revolution in my view downplay the devastation of environments through deforestation, crop planting, and mining, and the slaughter of animals for the leather, horn, ivory, and feather products we see in our museums. Products made or consumed in the UK from materials from abroad (sugar, tea, coffee, rubber, oils, furniture, jewellery) are separated from natural history galleries which present them as pristine products, separate from any supply chain, and they are also presented separately from anthropology galleries showing the peoples from those regions.

The rise of Europe as an industrial power in the $18^{\text {th }}$ and $19^{\text {th }}$ centuries through to its height before the Second World War, was based on the taming and exploitation of the natural resources of its own lands and especially of foreign lands. The great majority of the goods that people bought, many of them now shown in our local history museums, were made from natural materials from overseas. But because of this separation between seeming nature and culture, our museums show the products, innocently sitting on showcase shelves, as examples of industrial production and consumption, and they might sometimes show the animals and plants from which they were derived, but they are usually silent on the processes that led from one to the other.

This silence has led to the other, much bigger, reason that it matters: our slowness in confronting the enormity of the environmental and ecological challenges facing the planet at the moment. I hardly have to convince you of this, but for my purposes here it is useful to remind you of a few facts:

- Most scientists agree that we are in the middle of the $6^{\text {th }}$ mass extinction phase in the planet's history, where the rate of extinctions are far outpacing the background rate. The last mass extinction was in the Cretaceous, 66 million years ago.

- The current geological phase has been named The Anthropocene due to the visible impact of humans on the geological record.

- The last 5 years were the 5 hottest years on record around the world.

- The UN Intergovernmental Panel on Climate Change has warned that global warming of $2^{\circ} \mathrm{C}$ above pre-industrial levels could lead to increased droughts and flooding, sea level rises, ecosystem change, species loss and extinction on land and in the sea, reduced productivity for agriculture and fishing and climate-related poverty and disease.

- Climate change is likely to be the greatest cause of species extinctions this century. The IPCC says a $1.5^{\circ} \mathrm{C}$ average rise may put $20-30 \%$ of species at risk of extinction.

- Even if we significantly curb emissions in the coming decades, more than a third of the world's remaining glaciers will melt before the year 2100 . 
When it comes to sea ice, $95 \%$ of the oldest and thickest ice in the Arctic is already gone.

- Coral reefs harbour the highest biodiversity of any ecosystem globally and directly support over 500 million people worldwide, mostly in poor countries. But they are among the most threatened ecosystems on Earth, largely due to unprecedented global warming and climate changes, combined with growing local pressures.

- Globally, the largest single source of greenhouse gases from land use and agriculture is tropical deforestation - burning forests releases huge amounts of $\mathrm{CO} 2$ to the atmosphere, contributing to climate change.

- 500 million people live in areas that experience desertification - this degraded land is increasingly affected by climate change.

- More than 2 billion people already live in countries experiencing high water stress - climate change will make their lives harder (United Nations 2018).

- A study reported last month showing that air pollution particles had been found on the foetal side in every placenta analysed, in the form of thousands of particles of black carbon per cubic mm of tissue. 98\% of the world's population now live in places where air pollution is above WHO guidelines, something WHO calls "a public health emergency".

- Young people are reporting feeling overwhelmed by the stress and anxiety caused by these issues, and many are fearful of having children themselves.

- We are the first generation to know we are destroying the world, but we could be the last that can do anything about it (WWF).

So, the climate and ecological emergency and pollution of air and sea matter because they are an existential threat to us all.

To think about what they mean for museums, it is worth looking again at the familiar definitions to remind ourselves what their core purpose is.

Museums enable people to explore collections for inspiration, learning and enjoyment. They are institutions that collect, safeguard and make accessible artefacts and specimens, which they hold in trust for society (UK Museums Association 1998).

A museum is a non-profit, permanent institution in the service of society and its development, open to the public, which acquires, conserves, researches, communicates and exhibits the tangible and intangible heritage of humanity and its environment for the purposes of education, study and enjoyment (ICOM 2007).

To me, these now read as hopelessly inadequate: inspiration, learning and enjoyment seem rather weak in the light of the challenges we face.

Interestingly, ICOM proposed a new more dynamic definition at its triennial in Kyoto in 2019:

Museums are democratising, inclusive and polyphonic spaces for critical dialogue about the pasts and the futures. Acknowledging and addressing the conflicts and challenges of the present, they hold artefacts and specimens in trust for society, safeguard diverse memories for future generations and guarantee equal rights and equal access to heritage for all people. 
Museums are not for profit. They are participatory and transparent, and work in active partnership with and for diverse communities to collect, preserve, research, interpret, exhibit, and enhance understandings of the world, aiming to contribute to human dignity and social justice, global equality and planetary wellbeing.

Apart from the reference to "the challenges of the present" and "planetary wellbeing", it seems to me that this still reveals something of a blind-spot about climate and environment, with most of the emphasis being placed on social justice. However, it is generally acknowledged that social and environmental justice are inextricably inter-linked: wealthier nations and individuals are the largest emitters of carbon and the greatest polluters; while the poorer nations and people suffer disproportionately from the effects of climate change and pollution. So most environmentalists agree that tackling climate breakdown can only be done by simultaneously tackling social and economic issues such as poverty, human rights and the divide between the global north and south and the gap between rich and poor within specific societies. The climate activist movement around museums and galleries is also - interestingly - beginning to acknowledge that it is also necessary to engage with issues of racism and colonialism, seeing these as connected to climate issues. In relation to this, it is interesting to see a slight shift here: in England, Ironbridge Gorge, for example, is now being seen not only as the birthplace of the Industrial Revolution, but also as the birthplace of climate change. Perhaps we may be finally moving towards a more integrated museology.

The climate and ecological crises are therefore existential threats to museums: to the collections which distinguish them, to their buildings, to the people that work in them, and to their visitors. It is the greatest threat to the planet since nuclear weapons were invented, but unlike that threat, it requires not just high level diplomacy but a revolution in all aspects of everyone's lives.

But we are still doing relatively little about it. In the recent edited volume on "Museum Activism" (Janes, Sandell 2019), of the 34 articles, only one deals with the climate emergency and one with science museums and the issue of "neutrality" on sustainability issues.

Such thinking that does exist has come either from within academia (e.g. through UCL's Centre for Sustainable Heritage), or from groups outside the museum mainstream. Of the latter, the Climate Museum UK is pop-up museum with an online presence "creatively stirring responses to the climate and ecological emergency". In the USA, the "Natural History Museum" is an activist art collective operating a mobile pop-up museum out of Brooklyn, trying to connect movements to museums and museums to movements.

There's a Facebook group originating in Canada, called the Coalition of $\mathrm{Mu}$ seums for Climate Justice, highlighting current developments, with one of the founders being Robert Janes, who is probably the leading authority in relation to museums and climate change/ emergency. Ten years ago Janes published his book Museums in a Troubled World (Janes 2009), a passionate and prescient plea for 
museums to engage with issues such as climate change and environmental degradation, to avoid becoming totally irrelevant.

Along with wider groups such as Extinction Rebellion and more specific groups such as Culture Declares Emergency, activists and protesters are raising the profile of climate and ecology, and forcing museums to look more squarely at it.

So, what are museums themselves doing? Well, they're mainly doing what they have always been good at doing. Most have environmental action plans or similar, and have been trying to get their house in order through things like increasing recycling, reducing energy consumption, and generally continuing to do business as usual but more sustainably.

They have also, of course, being doing exhibitions, and of course this has helped raise the profile of environmental issues. Manchester Museum has done exhibitions on "Climate Control" and "Extinction", a topic that the Natural History Museum in London also tackled in an exhibition a couple of years ago. Art galleries have been in the forefront, such as Olafur Eliasson's melting glacier chunks last year outside Tate called Ice Watch and his current exhibition at Tate In Real Life. And Bristol museum recently covered its natural history specimens threatened with extinction.

This is a rapidly moving field though. Just at last October's UK Museums Association conference in Brighton we heard sessions on weaning ourselves off fossil fuels, mobilising young people to tackle climate change, turning the tide on ocean plastic, and had a keynote from Thomas Clayton-Muller, a senior campaigner for 360.org, to end fossil fuel consumption and embrace renewables.

We also heard about National Museum Wales's digital project Spring Bulbs for Schools, which each year engages more than 7,000 learners from schools across the UK in an investigation into how climate change affects the flowering dates of spring bulbs. The V\&A and other museums are documenting and collecting the climate movement such as Extinction Rebellion.

This is not enough though, as my Canadian colleague Douglas Worts suggests in an email to me:

It seems to me that very few museums have truly engaged with climate issues. I do see more museums wanting to seem like they are doing something positive - but always on their terms (i.e. creating exhibits or onsite programs on selected topics that contain contemporary issues, or greening projects). Encouraging museums to shift from an outputs model of public engagement to an outcomes/impact model is more than most museums can wrap their heads around.

So, I want to look a little deeper into why museums - including ones such as those with biological collections where it should be central - are finding it difficult "to shift from an outputs model to an outcomes/ impact model".

In addition to all of the reasons I outlined earlier, one of the real barriers to this is what Robert Janes has called museums' "authoritative neutrality", as he says "lest they fall prey to bias, trendiness and special interest groups". Now this is an important issue for museum trustees and staff: the high public trust in museums 
shown in surveys derives from the fact that they are long-term institutions with the public good in mind, above the shorter term interests of politics (but at the same time reliant on these for their funding decisions). They are supposed to be non-partisan, and unpolitical; even-handed and unbiased, neutral.

However, all critical analysis of museums, historically and today, show that they are not neutral: they have always reflected a partial view of history, usually in favour of the status quo and the more privileged social classes. Their founding history is political, from General Pitt Rivers, who wanted to teach people that social evolution was the way of the world so that they would not listen to "scatterbrained revolutionary suggestions" to the proponents of the UK's 1845 Museums Act, who were concerned to alleviate drunkenness by giving people an alternative to the tavern. Even today, as I have suggested, after over 30 years of new museology, we are not telling a neutral story about colonialism and slavery, for example.

Nevertheless museum senior managers and boards are nervous about taking a stance on contemporary issues because of this issue of seeming to be neutral. In the Museums Association's Code of Ethics, museum workers and boards are advised to:

- Ensure editorial integrity in programming and interpretation. Resist attempts to influence interpretation or content by particular interest groups, including lenders, donors and funders.

- Ensure that information and research presented or generated by the museum is accurate. Take steps to minimise or balance bias in research undertaken by the museum.

This is wise advice, when it comes, say, to accepting sponsorship from a company that might try to influence the content of an exhibition.

But why should shouting louder about the climate and ecological emergency be a problem? The science is overwhelmingly clear, and as I said earlier they are collectively planetary issues that affect literally everyone: museums, their staff, their visitors. I would argue that given such an existential threat, as institutions of the long-term, able to place what's going on into a wider context, it is an ethical imperative for museums to shout louder and take action.

So, my conclusion is that, sleepwalking as we are into the $6^{\text {th }}$ mass extinction and an overwhelming series of climate changes, museums must engage as a sector with these long-term global issues. And because the climate and ecological crisis is so interlinked with exploitation and consumption by humans, and the impacts of these changes are felt disproportionally by the disadvantaged, it is inevitable that museums have to address social justice issues as well.

Now, my next problem is one that I think is not confronted squarely enough, which is one of our sense of proportion. In our conferences and in our writings, museologists and museum workers can have a tendency to overclaim the impact of our work, convincing ourselves that what we are doing is going to save the world. There are of course some marvellous programmes undertaken by museums that 
engage and empower hard to reach audiences like recent refugees or differently abled people, and they undoubtedly make a real difference to participants' lives.

However, if we are honest with ourselves, the participants in these projects are actually a tiny proportion of the overall museum's audience. The vast majority of our visitors come not to have their lives changed but as part of an enjoyable outing with family and friends within a context of learning something new and perhaps being inspired. We like talking about socially engaged projects because social change is part of the accepted discourse and reward system of museology, and we feel better about ourselves when we're doing this kind of work. However, we have not found a way to translate this small scale but important work into mass participation that makes a change in the wider society.

This issue could be even more acute in relation to climate and ecology. What on earth, you could ask, do museums think they can do when the glaciers are melting and the rainforest is burning? Clearly there we need to have a sense of proportion. That is a good question to ask, as it reflects the questions we ask ourselves as individuals and as institutions. We want to do something, but in the face of the overwhelming nature of the issues, we just recycle stuff and try to cut down on using plastic.

So, we must be modest and realistic about what we can do in museums, but also focus on the contribution that museums can make as organisations. We are institutions with stewardship, conservation, the long term and the public interest at our heart so we do have a moral authority to speak. We do engage large numbers of people - about 100 million a year; more than go to church or go to football matches, apparently.

So, what can we realistically do?

So far, as noted, we've mainly concentrated on an output mode, and there is nothing wrong with this: doing exhibitions and programmes that highlight what is going on. There is now quite sophisticated thinking around messaging concerning the climate and ecological crisis, to ensure that it is not too apocalyptic and people switch off.

At the Horniman our audience is predominantly families with young children, and we know from talking to the parents, grandparents and carers, who bring them that they are actually very worried about the future that these children will be growing up in, and becoming adults in 2050 when we may or may not meet our carbon reduction targets. They want to do something but feel powerless. We have begun to engage with what we can therefore do to meet this concern, where we actually have a major series of issues with a large scale audience interested in engaging with them.

In response, we have recently changed the Horniman's mission to be:

The Horniman connects us all with global cultures and the natural environment, encouraging us to shape a positive future for the world we all share. 
To work towards this mission, we are now thinking through in detail what being a carbon neutral and biodiverse museum means. We declared a climate and ecological emergency in July, and are now working to embed the implications at a number of different levels:

We are renaming our Sustainability Working Group our Climate and Ecological Action Group, with a brief to accelerate actions. We are encouraging our staff to take actions in a personal capacity - for example by having a bike to work scheme and introducing lunchtime sessions on living sustainably.

As organisation internally we are switching to Green energy moving away from single use plastics through the use of compostable serveware and canned water in our cafe and involvement in the Mayor of London's Refill campaign. We compost $97 \%$ of our garden waste on-site in our gardens, as well as the compostable serveware and food waste.

Nearly 200,000 litres of aquarium water is reused for irrigating the grounds. We have developed an online Green visitor guide which outlines our environmental actions. Our Aquarium is actually unique in being the first in the world to successfully breed coral in captivity: we have now been able to breed six times a year rather than the once a year in the oceans, thereby holding out the potential of selectively breeding corals more tolerant of warmer waters. We are partnering with Florida Aquarium to scale up the process and hope to eventually be able to repopulate bleached coral reefs.

In our programming we have developed a series of interventions particularly around plastic pollution, in the Aquarium and in the Natural history gallery. We showed the first UK exhibition of Meltdown: a visualization of climate change by Project Pressure, which shows artworks related to vanishing glaciers, whose disappearance can be $100 \%$ attributed to climate change.

We used the opening of the exhibition to launch our Climate and Ecological Manifesto, which sets out our ethos and actions for the future.

So far, though, much of what we are doing is focused on getting our house in order and working in output mode like most of our colleagues.

We are now working on a ten year plan for the museum which will aim at delivering our mission in full, and engage the public more actively in the kind of issues I have described. Key to this is a project we are calling Nature and Love. The reason we have called it that is because research shows that many if not most people are turned off by the enormity of climate and ecological issues, feeling disempowered and unmotivated. One of the most potentially effective ways of overcoming this is to appeal to people's love of family, particularly the next generation. At the Horniman, because some $70 \%$ of our audience is families with young children, this is especially powerful because we know that parents, grandparents and carers are really worried about the future these children are going to inherit. Given that the word most often associated with the Horniman is "love" (as in "I love the Horniman") then this is a powerful call to action. 
What we plan to do is to refurbish our Natural History Gallery, which is some 60 years old and makes no mention of people's influence on environment and climate, at the same time as updating our Aquarium with the coral breeding message, and linking all of this with our outside spaces, where we'll do more tree planting and planting for diversity, open a new nature-themed play area which will open up access to our hidden half-mile nature trail, which will also be planted to encourage biodiversity. We will work with community groups, including those active in climate and pollution issues, to place our collections in their colonial context, show the interrelationship between people and planet over the centuries and the effects of this, and - crucially - adopt an outcomes-based approach which will see visitors encouraged to take actions in their own lives to address the climate and ecological emergency.

A key part of this - and something we are still working on - will be a space which we are calling at the moment an Action Centre. It will provide a platform for community groups engaging with issues like air pollution (and we will have a live pollution monitor showing data for the South Circular outside the museum), practical advice on how to live more ethically and sustainably, etc. We will be forming an Environmental Champions group of people who will commit to undertaking actions and supporting each other to do these.

A key driver of all of this is the idea that we should be empowering our visitors to be active citizens and not passive consumers. One of the daunting aspects of engaging with the climate and ecological emergency is that it can seem that, even if we encourage more people to live sustainably, the real changes have to come at the level of government, large corporations and financial institutions. We think that part of our role is to encourage people not only to make changes in their own lives, but to use their power as citizens to lobby for change at these larger scales, through their votes, through campaigning and even actions such as strikes. On this, it is interesting to note that Chicago's Field Museum has been very vocal in its support for the recent climate strikes...

What does this mean for us in museums?

On a practical level, it means really engaging with some tricky issues, such as how to work internationally when you are trying to reduce your carbon emissions. I was determined to travel to Krakow by train to reduce my carbon footprint, but instead of 2 hours by Easyjet at $£ 100$ it is 30 hours with an overnight in Berlin and would have taken four days out of my week and cost three times as much! We are also trying to develop new ethical partnerships with museums in Africa and to do that we feel you have to meet face to face before doing videoconference.

For the large museums it will mean really engaging both with sponsorship by fossil fuel companies and for all of us thinking about the banks we use and their own ethical investment policies. It will also mean thinking about where research funding comes from (give Manchester GOG example?). And it will mean really living our values, thinking through what a new kind of integrated ethical museol- 
ogy might look like, and what it will really take for museums to be carbon and pollution-neutral and more biodiverse.

So here are some potential principles for an ethical museum ecology:

- We need a new vision for museums that is carbon and pollution neutral, and biodiverse.

- While we are only a tiny sector in terms of tackling these challenges, as institutions of the long term museums have a leadership role and an ethical imperative in engaging with the urgency of climate, pollution and biodiversity issues.

- Social and environmental justice issues are interlinked and should be viewed holistically.

- "Authoritative neutrality" is an illusion and has prevented museums from engaging with critical issues.

- Collectively museums and their audiences can make a significant impact in addressing these issues through their actions as organisations and individuals and by empowering people as citizens.

- Being carbon and pollution neutral and encouraging biodiversity means doing things radically differently.

- It is better to start the journey and be accused of being hypocritical and imperfect rather than doing nothing and waiting to be perfect.

- Accepting that the museum of the future - whilst retaining its collection at its heart - will be more focused on issues than objects.

\section{Conclusion}

We need to move towards what I would like to call an Integrated, or holistic museology, one that overcomes the historic nature-culture divide that since the Enlightenment has downplayed the vital importance of "seeming nature" in and of itself. We need a "turn to nature and environment" similar to the "turn to the body" that permeated humanities subjects in the 1980s and 90s. This holistic museology will show the interconnectedness of social history in the UK with colonial exploitation of people, animals, plants and minerals, and thoroughly avow the impact of this on UK history and institutions such as museums. The turn to nature and environment will also allow museums to engage with the historical roots of the current climate and ecological crisis and recognise that as public institutions of the long term, museums have an ethical imperative to engage actively with these issues.

Whilst continuing with a certain amount of outputs such as exhibitions and public programmes, museums will need to focus much more on outcomes - such as how they as organisations and how their visitors empower themselves to take positive actions. 


\section{Bibliography}

\section{Cameron D.}

1971 The Museum, a Temple or the Forum, "Curator", vol. 14 (1), p. 11-24.

Davis P.

1999 Ecomuseums: A Sense of Place, Leicester.

Varine H. de

1978 Lécomusée, “Gazette”, vol. 11, no. 2, printemps, p. 29-40.

Gandy M.

2002 Concrete and Clay, Cambridge.

Haraway D.

1984 Teddy Bear Patriarchy: Taxidermy in the Garden of Eden, New York City 19081936, “Social Text”, no. 11, p. 20-64.

Janes R., Sandell R.

2019 Museum Activism, New York.

Pearce S. (ed.)

1989 Museum Studies in Material Culture, Leicester.

Swyngedouw E.

2013 The Non-Political Politics of Climate Change, "ACME: An International Journal for Critical Geographies", vol. 12 (1), p. 1-8.

Janes R.

2009 Museums in a Troubled World: Renewal, Irrelevance or Collapse?, London-New York. 